\title{
Gesneriaceae da Serra da Pedra Branca, Caldas, Estado de Minas Gerais, Brasil
}

\author{
๑Luciana Carvalho Pereira ${ }^{1,3}$, Munike Gonçalves de Rezende ${ }^{1}$, Alain Chautems ${ }^{2}$ e Luiz Menini Neto ${ }^{1}$
}

Recebido: 30 abril 2019; aceito: 9 outubro 2019

Como citar: Pereira, L.C., Rezende, M.G., Chautems, A. \& Menini Neto, L. 2019. Gesneriaceae da Serra da Pedra Branca, Caldas, Estado de Minas Gerais, Brasil. Hoehnea 46: e472019. http://dx.doi.org/10.1590/2236-8906-47/2019.

\begin{abstract}
Gesneriaceae of the Serra da Pedra Branca, Caldas, Minas Gerais State, Brazil). The Serra da Pedra Branca (SPB) is located in the southern part of the of Minas Gerais State, in the municipality of Caldas (21 ${ }^{\circ} 8^{\prime}-21^{\circ} 55^{\prime}$ 'S and $46^{\circ} 24^{\prime}-$ $\left.46^{\circ} 22^{\prime} \mathrm{W}\right)$. Inserted in the Atlantic Domain and considered a priority area for the flora conservation in Minas Gerais, SPB is a remarkable component of the local landscape relief,, with elevations ranging from 1100 to 1780 m.s.m. State It presents a mosaic composed of high altitude fields (which occupies the largest extent), Montane Semi-deciduous Forest, Dense HighMontane Ombrophilous Forest, and Mixed Ombrophilous Forest. The family Gesneriaceae is represented in the SPB by five species of the genus Sinningia: S. aggregata (Ker Gawl.) Wiehler, S. allagophylla (Mart.) Wiehler, S. douglasii (Lindl) Chautems, S. magnifica (Otto \& A .Dietr.) Wiehler), and S. striata (Fritsch) Chautems. An identification key, morphological descriptions, illustrations, ecological comments, and taxonomic and geographic distribution of the species are presented. Keywords: high altitude fields, conservation, flora, Serra da Mantiqueira
\end{abstract}

RESUMO - (Gesneriaceae da Serra da Pedra Branca, Caldas, Estado de Minas Gerais, Brasil). A Serra da Pedra Branca (SPB) localiza-se no sul do Estado de Minas Gerais, no município de Caldas (21 $58^{\prime}-21^{\circ} 55^{\prime} \mathrm{S}$ e $\left.46^{\circ} 24^{\prime}-46^{\circ} 22^{\prime} \mathrm{W}\right)$. Inserida no Domínio Atlântico e considerada área prioritária para a conservação da flora no Estado de Minas Gerais, é uma feição marcante no relevo, com cotas altimétricas entre 1100 e 1780 m.s.m. Apresenta um mosaico composto por campos de altitude (o qual ocupa maior extensão na área), Floresta Estacional Semidecidual Montana, Floresta Ombrófila Densa Alto-Montana e Floresta Ombrófila Mista. A família Gesneriaceae está representada na SPB por cinco espécies do gênero Sinningia: S. aggregata (Ker Gawl.) Wiehler, S. allagophylla (Mart.) Wiehler, S. douglasii (Lindl) Chautems, S. magnifica (Otto \& A.Dietr.) Wiehler) e S. striata (Fritsch) Chautems. São apresentadas chave de identificação, descrições morfológicas, ilustrações, comentários ecológicos, taxonômicos e de distribuição geográfica das espécies.

Palavras-chave: campos de altitude, conservação, flora, Serra da Mantiqueira

\section{Introdução}

Gesneriaceae se distribui pela zona pantropical e mais raramente em zonas temperadas. A mais recente proposta de classificação para a família reconhece três subfamílias, com cerca de 3500 espécies distribuídas em 150 gêneros (Weber et al. 2013). O Brasil constitui um centro secundário de diversidade, tendo aproximadamente 28 gêneros englobando 221 espécies (BFG 2018). Dois terços destes táxons encontram-se na região extra-amazônica, com uma importante concentração e forte endemismo na região sudeste, habitando principalmente as matas úmidas brasileiras (Chautems 1988, 1991, Chautems \& Matsuoka 2003). São ervas, subarbustos ou arbustos com alto grau de epifitismo (cerca de $20 \%$ das espécies conhecidas), podendo apresentar estruturas para adaptação às estações secas, nas formas de tubérculos e rizomas (Wiehler 1983, Perret et al. 2007). A polinização é feita principalmente por beija-flores, estima-se que $60 \%$ das Gesneriaceae sejam polinizadas por essas aves, podendo ocorrer também por abelhas, em casos mais raros por morcegos e mariposas (Camargo et al. 2011, Serrano-Serrano et al. 2017, Pansarin \& Pansarin

1. Universidade Federal de Juiz de Fora, Instituto de Ciências Biológicas, Depto de Botânica, Rua José Lourenço Kelmer, s/n, 36036-900 São Pedro, Juiz de Fora, MG, Brasil

2. Jardin botaniques de la Ville de Genève, Chemin de l'Impératrice 1, 1292 Pregny-Chambésy, Suíça

3. Autor para correspondência: lucianacpereira.bio@gmail.com 
2018). Apresentam um forte potencial ornamental e são utilizadas na medicina popular (Wiehler 1995, Souza \& Lorenzi 2012).

O conhecimento sobre as Gesneriaceae no Estado de Minas Gerais pode ser considerado reduzido, se levada em consideração a extensão deste Estado. Podem ser citados estudos realizados em áreas de altitude, como nos Parques Nacionais da Serra do Cipó e do Caparaó (Araújo et al. 2004, Leoni \& Chautems 2004) na Cadeia do Espinhaço (Araújo et al 2005) e nos Parques Estaduais da Serra do Brigadeiro, do Ibitipoca, da Serra Negra da Mantiqueira e da Serra do Papagaio (Leoni et al. 2005, Blaser et al. 2011, 2012, Pereira et al. 2013). Assim, dados sobre a distribuição e conservação ainda são escassos, sendo de suma importância a realização de inventários, como fontes de maiores informações e conseqüentemente a conservação dos ambientes que as abrigam.

Neste sentido, a Serra da Pedra Branca é uma área que merece atenção e, desde o século XIX, diversos naturalistas, com destaque para Anders Fredrik Regnell, vêm registrando coletas nesta localidade mostrando a rica flora vascular, formação geológica peculiar e que também se apresenta distinta do restante da Serra da Mantiqueira (Mota Machado \& Menini Neto 2010, Rosa et al. 2012, Rezende et al. 2013). Nesta região predominam os campos de altitude, em um mosaico formado com as florestas estacionais e ombrófilas (incluindo fragmentos de floresta ombrófila mista). Esta área é considerada de destacada importância biológica de acordo com o Mapa de Áreas Prioritárias para a Conservação da Flora de Minas Gerais (Drummond et al. 2005).

Este estudo teve como objetivo realizar o inventário das Gesneriaceae da Serra da Pedra Branca, como contribuição à sua taxonomia e ampliação do conhecimento da flora do Estado de Minas Gerais, Brasil. Para tal são apresentada chave de identificação, descrições morfológicas, ilustrações, comentários ecológicos, taxonômicos e de distribuição geográfica das espécies.

\section{Material e métodos}

A Serra da Pedra Branca situa-se na Serra da Mantiqueira, no município de Caldas, sul do Estado de Minas Gerais (Várzea 1942), (21ํ5' S - 46²3'W) (figura 1). A altitude varia de 950 a 1900 m.s.m. (Conforti et al. 2007), o clima é do tipo tropical de altitude $(\mathrm{Cwb})$ que apresenta verão chuvoso (Köppen et al. 1928). A região integra a formação geomorfológica do Planalto Dissecado do Sul de Minas e está inserida na porção Meridional da Serra da Mantiqueira (CETEC 1983, Machado Filho et al. 1983).

A Área de Proteção Ambiental (APA) Santuário Ecológico da Pedra Branca foi criada através do decreto Municipal no 1973, de 29 de dezembro de 2006 e possui aproximadamente 11.955 ha abrangendo o distrito de Pocinho do Rio Verde, a área rural sul de Caldas e a Serra da Pedra Branca, que ocupa a parte centro sudeste da APA. A vegetação na Serra da Pedra Branca apresenta-se como um mosaico formado por áreas de floresta estacional semidecidual montana e alto-montana e campos de altitude. Há também elementos de floresta ombrófila mista altomontana, com a presença de espécimes de Araucaria angustifolia (Bertol). Kuntze (Araucariaceae) (Conforti et al. 2007).

As coletas específicas para o presente estudo foram realizadas mensalmente, entre março de 2008 e fevereiro de 2009, na APA Santuário Ecológico da Pedra Branca, no município de Caldas. Os espécimes coletados foram incorporados ao Herbário Professor Leopoldo Krieger (CESJ) da Universidade Federal de Juiz de Fora. As espécies foram identificadas através de consulta à bibliografia especializada e comparações com materiais do acervo dos herbários CESJ, G, K, P, R, S, SP e US. Os registros da Serra da Pedra Branca disponíveis nestes herbários também foram utilizados na descrição das espécies.

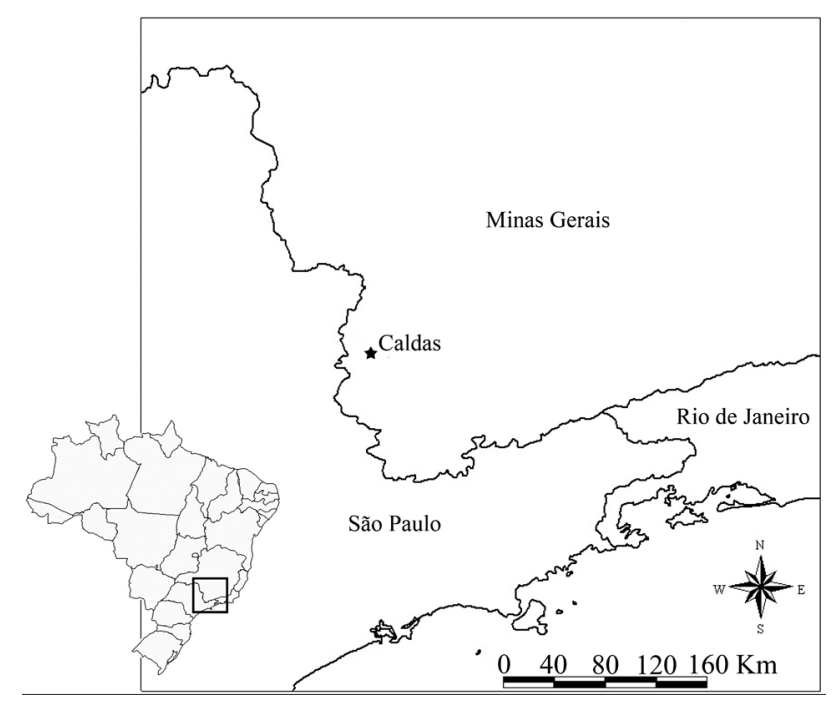

Figura 1. Localização da Serra da Pedra Branca, Município de Caldas, MG, Brasil.

Figure 1. Location of Serra da Pedra Branca, Municipality of Caldas, MG, Brazil. 


\section{Resultados e Discussão}

Foram registradas cinco espécies de Gesneriaceae, todas pertencentes ao gênero Sinningia: S. aggregata (Ker Gawl.) Wiehler, S. allagophylla (Mart.) Wiehler, S. douglasii (Lindl.) Chautems, S. magnifica (Otto \& A. Dietr.) Wiehler $e$ S. striata (Fritsch.) Chautems (figura 2). Dentre as cinco espécies encontradas, quatro são saxícolas e uma ocorre como epifítica (tabela 1). As espécies foram coletadas tanto no campo de altitude, em afloramentos graníticos ou entre gramíneas, quanto no interior da floresta nebular.

Estudos semelhantes no Estado de Minas Gerais também registraram Sinningia como um dos gêneros mais representativos (tabela 2): na Cadeia do Espinhaço e no Parque Nacional (PN) da Serra do Cipó, região central do Estado de Minas Gerais (MG) (Araújo et al. 2004, 2005); no Parque Estadual (PE) da Serra do Papagaio, no sul de MG (Pereira et al. 2013); no PE de Ibitipoca e PE da Serra Negra da Mantiqueira, no sudeste de MG (Blaser et al. 2011, 2012) e na APA da Serra de São José, campos das vertentes de MG, PE da Serra do Brigadeiro e PN do Caparaó, região nordeste de $\mathrm{MG}$.

A representatividade do gênero Sinningia se justifica por ser um dos mais diversos da família, com distribuição exclusiva na Região Neotropical, concentrada, sobretudo, na Floresta Atlântica, onde ocorrem 69 das 75 espécies reconhecidas para o Brasil (BFG 2018). No entanto, chama a atenção a ocorrência apenas deste gênero na Serra da Pedra Branca, enquanto nos estudos supracitados, outros gêneros de ocorrência comum também são registrados, como Codonanthe, Nematanthus, Paliavana, e Vanhouttea entre outros. Por outro lado, uma grande proporção de espécies do gênero também pode ser observada no Parque Estadual da Serra do Papagaio (Pereira et al. 2013), pois dentre as oito espécies registradas, seis pertencem ao gênero Sinningia, destacando a importância da região sul do Estado para as espécies deste gênero.

Gesneriaceae Rich. \& Juss. ex DC., Essai Prop. Med. P1. 2:192. 1816.

Ervas geralmente perenes, subarbustos ou arbustos, terrícolas, saxícola ou epífiticas, podendo apresentar estruturas para adaptação às estações secas, na forma de tubérculos ou rizomas; caule aéreo herbáceo ou lenhoso, ereto ou pendente. Folhas simples, opostas, às vezes verticiladas, isófilas ou anisófilas, pecioladas ou subsésseis; lâmina membranácea a crassa, margem inteira ou denteada a serreada. Inflorescência axilar ou terminal, cimosa ou flores solitárias; brácteas pequenas, raramente ausentes. Flores geralmente vistosas, zigomorfas, raramente actinomorfas, bissexuadas, ressupinadas ou não; 5 sépalas, pouco unidas na base, às vezes até $1 / 3$ ou quase $1 / 2$ do comprimento da corola, verdes ou coloridas, inteiras a denteadas; corola gamopétala, tubulosa, colorida, raramente alva, às vezes gibosa na base, ou junto ao ápice, lobos subiguais ou desiguais, eretos ou patentes; estames 4 , inclusos, às vezes com 1 estaminódio, anteras unidas, rimosas, às vezes poricidas; disco anular ou constituído de 1-5 glândulas; ovário súpero a semi-ínfero, 2-carpelar, 1-locular, placentação parietal; estilete simples, estigma estomatomórfico, 2-lobado ou claviforme. Fruto baga ou cápsula seca ou carnosa, 2-valvar; sementes numerosas, geralmente elípticas, estriadas (Barroso et al. 1991, Chautems 1993, Souza \& Lorenzi 2012).

\section{Chave para as espécies de Gesneriaceae registradas na Serra da Pedra Branca}

1. Inflorescência densa, espiciforme; pedicelo 1-2 mm compr. 2. Sinningia allagophylla

1. Inflorescência em cimeira; pedicelo 0,8-3,5 cm compr.

2. Lâmina foliar ovada, flores com corolas vermelhas

3. Caule aéreo 13-45 cm compr.; cálice com sépalas ovadas; corola não bilabiada, 2,4-3,4 cm compr.

3. Caule aéreo ca. $70 \mathrm{~cm}$ compr.; cálice com sépalas triangulares a lanceoladas; corola bilabiada, $3-4,6 \mathrm{~cm}$ compr. 4. Sinningia magnifica

2. Lâmina foliar elíptica a lanceolada, flores com corolas róseas com máculas vináceas ou róseo-escuras 4. Erva rupícola; folhas 3-verticiladas dispostas ao longo do caule, corola 2,8-3,5 cm compr.

4. Erva epifítica; folhas 6-verticiladas dispostas em um ou dois verticilos no ápice do caule, corola 3,5-4,6 cm compr. 

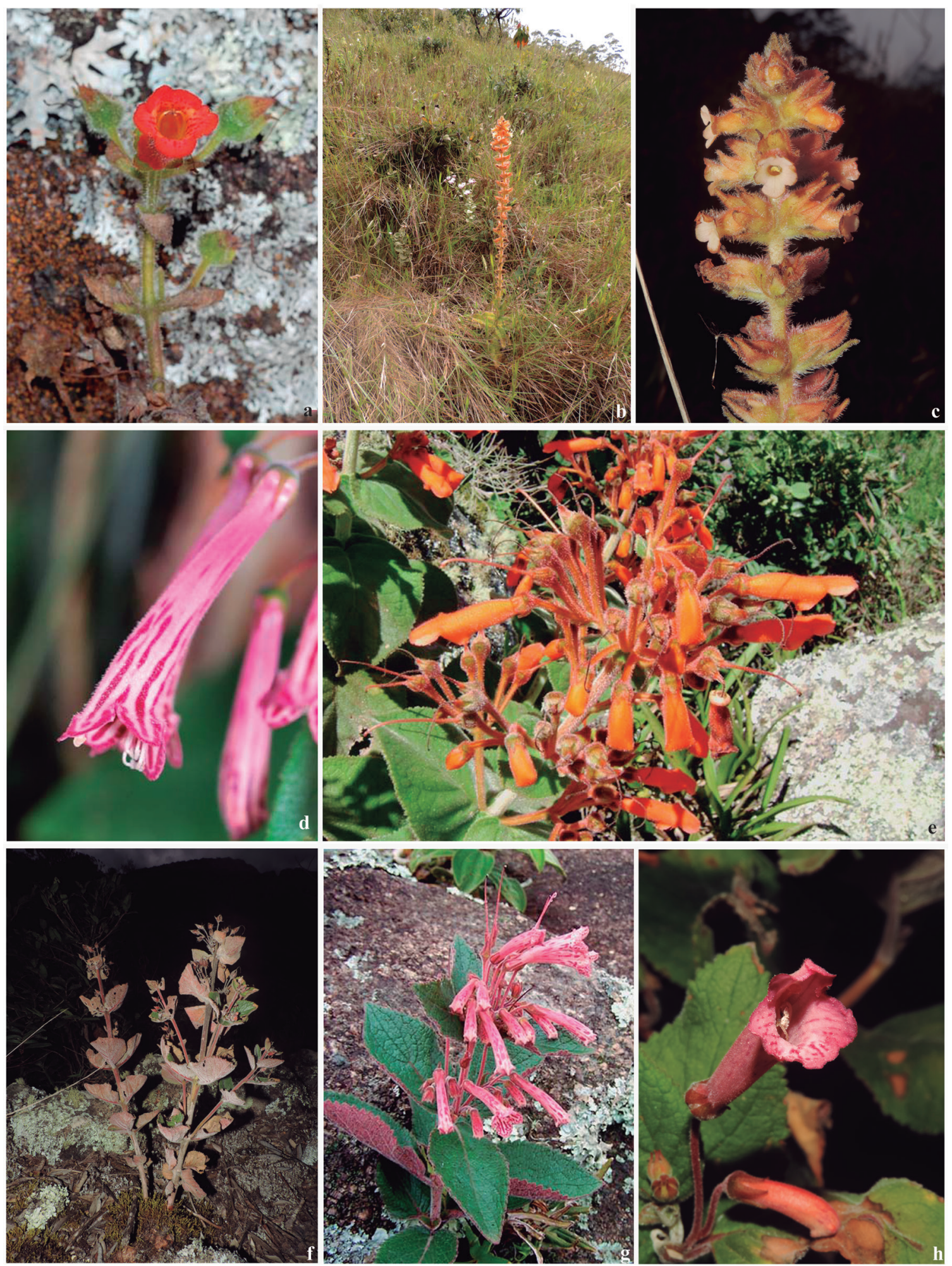

Figura 2. Espécies de Gesneriaceae encontradas na Serra da Pedra Branca. a. Sinningia aggregata (Foto: P.H. Nobre). b, c. S. Allagophylla (Foto: Diego Gonzaga). d. S. douglasii (Foto: Luiz Menini Neto). e-s. S. magnifica (Foto: Munike G. Rezende). f, g e h. S. striata (Foto: f, h. Diego Gonzaga. g. Munike G. Rezende).

Figure 2. Gesneriaceae species found in the Serra da Pedra Branca. a. Sinningia aggregata (Photo: P.H. Noble). b, c. S. Allagophylla (Photo: Diego Gonzaga). d. S. douglasii (Photo: Luiz Menini Neto). e-s. S. magnifica (Photo: Munike G. Rezende). f, g and h. S. striata (Photo: f, h. Diego Gonzaga. G. Munike G. Rezende). 
Tabela 1. Gesneriaceae registradas na Serra da Pedra Branca, Caldas.

Table 1. Gesneriaceae registered in Serra da Pedra Branca, Caldas.

\begin{tabular}{lcc}
\hline Espécies & Habitat de ocorrência na Pedra Branca & N $^{\circ}$ de registro \\
\hline Sinningia aggregata & Saxícola no campo de altitude & CESJ 49840 \\
Sinningia allagophylla & Saxícola entre gramíneas no campo de altitude & CESJ 52399 \\
Sinningia douglasii & Epifítica no interior de floresta nebular & CESJ 52157 \\
Sinningia magnifica & Saxícola em afloramentos graníticos no campo de altitude & CESJ 50454 \\
Sinningia striata & Saxícola em afloramentos graníticos no campo de altitude & CESJ 52505 \\
\hline
\end{tabular}

Sinningia Nees Ann. Sci. Nat. (Paris) 6: 297. 1825

Ervas, arbustos ou subarbustos, com presença de tubérculo perene, caule anual, destacando-se pela variabilidade de ambientes ou substratos que ocupam. Podem ocorrer em diversos tipos vegetacionais, como florestas pluviais, montanas e estacionais, restingas, estepes, savanas, campos rupestres e campos de altitude. Quanto ao substrato, as espécies podem ser terrícolas, saxícolas, paludícolas, rupícolas ou epífiticas (Chautems 2008, Araújo \& Chautems 2015).

Sinningia é um gênero Neotropical com 80 espécies, sendo que no Brasil encontra-se 75 espécies, das quais 65 são endêmicas. A maioria está distribuída na Floresta Atlântica nas regiões Sudeste e Sul do país, área considerada centro de diversidade do gênero (Perret et al. 2006, Araújo \& Chautems 2015, BFG 2018).

Sinningia aggregata (Ker Gawl.) Wiehler, Selbyana 1: 32.1975.

Figura $2 \mathrm{a}$

Erva rupícola; caule aéreo 13-45 cm compr., herbáceo, anual, ereto, verde, simples ou ramificado, glanduloso-pubescente. Folhas opostas, levemente anisófilas; pecíolo 3-6 mm compr., glandulosapubescente; lâmina 3,5-8,5 × 2-4 cm, verde, ovada, membranácea, ápice e base subagudos, margem crenada, glandulosa-pubescente nas duas faces, 4-9 pares de nervuras secundárias. Inflorescência nas axilas das folhas, cimeiras de 1-8 flores. Flores pediceladas, pedicelo 0,8-3 cm compr., verde a avermelhado, pubescente; cálice verde, sépalas 4-5 × 2-3 mm, ovada, margem inteira, pubescente; corola 2,4-3,4 cm compr., não bilabiada, tubulosa, levemente zigomorfa, vermelho-claro, pubescente, base intumescida com duas protuberâncias dorsalmente, abruptamente constrita e depois progressivamente alargando próximo à abertura, lacínios subiguais, 1-2 $\times 2-3 \mathrm{~mm}$, patentes, glabrescentes; estames inclusos a levemente exserto, filetes creme, 2-2,3 cm compr., anteras unidas em retângulo; estilete incluso a pouco exserto, ca. $2 \mathrm{~cm}$ compr., avermelhado; nectário formando 5 glândulas as 2 dorsais mais desenvolvidas e unidas, as outras 3 pouco desenvolvidas e isoladas. Frutos com cálice persistentes, $0,8-1,5 \mathrm{~cm}$ compr., ovoides, secos do tipo cápsula.

Sinningia aggregata está distribuída desde o leste do Paraguai, ocorrendo nas regiões Norte (TO), Centro-Oeste, Sul e Sudeste do Brasil (Araújo \& Chautems 2015, BFG 2018). Pode ser reconhecida pela presença de indumento glandular e aromático (Chautems et al. 2000). Floresce durante todo o ano e frutifica em janeiro e outubro (Araújo et al. 2005). Na Serra da Pedra Branca foi observada com flores nos meses de setembro a março, no campo de altitude, entre rochas a ca. $1000 \mathrm{~m}$ altitude.

Material examinado: BRASIL. MinAS GERAIS: Caldas, Pocinhos do Rio Verde, Serra da Pedra Branca, 17-XII-1989, fl., A. Chautems et al. 367 (G, SP, US); 28-III-2008, fl. e fr., Rezende et al. 122 (CESJ); 24-I-2009, fl., T.M. Machado et al. 124 (CESJ); 10-II-2009, fl., Rezende et al. 348 (CESJ).

2. Sinningia allagophylla (Mart.) Wiehler, Selbyana 1: 32.1975.

Figuras 2b-c

Erva rupícola ou terrícola; caule aéreo $27-53 \mathrm{~cm}$ compr., herbáceo, anual, ereto, verde a avermelhado no ápice, simples, velutino. Folhas opostas ou 3-verticiladas, levemente anisófilas; pecíolo 1-3 mm compr., pubescente; lâmina 2-8 × 0,6-2,5 cm, verde, ovada-oblonga, cartácea, ápice e base obtusos, margem crenada, face adaxial tomentosa, face abaxial pubescente, 5-8 pares de nervuras secundárias. Inflorescência terminal, espiciforme, séssil, $18-22 \mathrm{~cm}$ compr., geralmente compacta no início da floração, tornando-se laxiflora no final; brácteas mais curtas que as flores. Flores únicas, na axila de uma bráctea, 
pedicelo inconspícuo; cálice verde a avermelhado, sépalas 5-8 × 1-2 mm, subiguais, triangulares, margem inteira, pubescente; corola $1,5-1,8 \mathrm{~cm}$ compr., não bilabiada, urceolada-tubulosa, levemente actinomorfa, rosa-alaranjada, pubescente, lacínios subiguais, 1-1,4 mm compr., patentes, glabrescentes; estames inclusos, filetes creme, $0,6-0,8 \mathrm{~cm}$ compr.; anteras unidas em retângulo; estilete incluso a levemente exserto, ca. 6-9 mm compr., creme; nectário formado de 5 glândulas, as 2 dorsais mais desenvolvidas e unidas, as outras 3 pouco desenvolvidas e isoladas. Frutos ca. 1,5 cm compr., ovoides, secos do tipo cápsula.

Sinningia allagophylla apresenta ampla distribuição geográfica, ocorrendo no Paraguai, Uruguai, Argentina e no Brasil nas regiões CentroOeste, Sul e Sudeste (Araújo \& Chautems 2015, BFG 2018). Diferencia-se das demais espécies de Sinningia da Serra por ser a única com inflorescência espiciforme. A floração ocorre de setembro a fevereiro, com pico de outubro a janeiro (Chautems \& Matsuoka 2003). Na Serra foi observada com flores de outubro a novembro. Encontrada em meio a touceiras de gramíneas no campo de altitude ca. $1000 \mathrm{~m}$ altitude.

Material examinado: BRASIL. MinAs GeraIs: Caldas, Pocinhos do Rio Verde, 17-XII-1989, fl., A. Chautems et al. 369 (G, SP, US);21-X-2008, fl., M.G.Rezende et al. 221 (CESJ); 22-XI-2008, fl., M.G.Rezende, et al. 252 (CESJ, G).

Material adicional: BRASIL. MinAs GERAIS: Baependi, Parque Estadual da Serra do Papagaio, próximo ao Centro de apoio ao pesquisador, 13-IV-2012, fl. e fr. F.R.G.Salimena et al. 3416 (CESJ).

\section{Sinningia douglasii (Lind1.) Chautems, Candollea} 45: 382. 1990.

Figura 2d

Erva epifítica; caule aéreo 18-20 cm compr., herbáceo, anual, ereto, verde a vináceo, simples, pubescente. Folhas 6 -verticiladas às vezes encimadas por um segundo verticilo de três folhas menores de 4-8 cm acima do primeiro, levemente anisófilas; pecíolo 1,4-2,6 cm compr., pubescente; lâmina 2,6-7 × 1-4 cm, verde, lanceolada, cartácea, ápice agudo, base obtusa, margem irregularmente crenada a serreada, pubescente, 5-8 pares de nervuras secundárias. Inflorescência com pedúnculo de 6,5-15 cm compr., cimeiras de 2-3 flores em verticilo. Flores pediceladas, pedicelo $2-3,5 \mathrm{~cm}$ compr., avermelhado, pubescente; cálice verde, sépalas $9,5 \times 3,1 \mathrm{~mm}$, triangulares, margem inteira, pubescente; corola 3,5-4,6 cm compr., não bilabiada, tubulosa, actinomorfa, rósea com estrias vináceas, pubescente, base intumescida com 5 protuberâncias, em seguida constrita, depois progressivamente alargada, lacínios subiguais, 4,2-5,2 × 5,1-5,8 mm, eretos, pubescente; estames inclusos, filetes róseoclaros, 1,8-2,1 cm compr., anteras unidas em disco; estilete incluso, 3,1-3,3 cm compr., róseo; nectário formado de 2 glândulas dorsais isoladas. Fruto ca. 1,7 cm compr., ovoide, secos do tipo cápsula.

Sinningia douglasii apresenta distribuição restrita às florestas úmidas das regiões Sudeste e Sul do Brasil, ocorrendo também no Noroeste da Argentina (Araújo \& Chautems 2015, BGE 2018). Diferencia-se das demais espécies da Serra por apresentar folhas 6-verticiladas, às vezes encimadas por um segundo verticilo de 3 folhas menores logo acima do primeiro e pela inflorescência em cimeiras verticilada. A floração ocorre de agosto a março com pico de floração de setembro a dezembro (Chautems \& Matsuoka 2003). $\mathrm{Na}$ Serra foram coletados exemplares com botões em setembro, no interior da mata nebular ca. $1760 \mathrm{~m} \mathrm{de}$ altitude.

Material examinado: BRASIL. Minas Gerais: Caldas, Pocinho do Rio verde, Serra da Pedra Branca, 22-X-1864, fl., A.F. Regnell. 834 (USP); XII-1989, fl., A. Chautems et al. 365 (G, SP); 14-IX-2008, fl. e fr., Valente et al. 504 (CESJ).

4. Sinningia magnifica (Otto \& A.Dietr.) Wiehler, Selbyana 1:32. 1975

Figura 2e

Erva rupícola; caule aéreo $70 \mathrm{~cm}$ compr., herbáceo, anual, ereto, avermelhado; simples, velutino, tricomas alvos a avermelhados. Folhas opostas, anisófilas; pecíolo 0,2-1,2 cm compr., pubescente; lâmina 3-9,5 × 3-7,5 cm, verde-clara, largamente ovada, cartácea, ápice agudo, base obtuso-cordada, margem crenada a denteada, face adaxial velutina, face abaxial canescente-tomentosa, 5-7 pares de nervuras secundárias. Inflorescência com pedúnculo de 1,4-6 cm compr., cimeira de 2-12 flores, nas axilas de folhas progressivamente menores no ápice. Flores pediceladas, pedicelo 1,6-3 cm compr., vináceo, velutino; cálice vermelho, sépalas ca. 4-6 mm, triangulares a lanceolados, margem inteira, pubescente; corola 3-4,6 cm compr., bilabiada, cilíndrica, levemente zigomorfa, vermelho vivo com mácula vinácea no interior do tubo ventral, pubescente 
velutina, base intumescida com cinco protuberâncias pequenas, em seguida abruptamente constrita, depois progressivamente alargada, dois lacínios dorsais, unidos, eretos 12-13 $\times$ 5-6 mm, formando uma gálea, dois laterais ca. $2 \times 7-8 \mathrm{~mm}$, um ventral 1-2 $\times 4-5 \mathrm{~mm}$; estames um pouco mais curtos que os lacínios superiores, filetes avermelhados ca. $3,0 \mathrm{~cm}$ compr., esparsamente pilosos, anteras unidas em disco; estilete tão longo quanto o lábio superior, ca. $4,2 \mathrm{~cm}$ compr., alvo; nectário formado de 2 glândulas dorsais, unidas. Frutos ca. 1,4 cm compr., ovoide, secos do tipo cápsula.

Sinningia magnifica é endêmica do Brasil, ocorrendo nos campos rupestres e de altitude dos Estados da Região Sudeste (Araújo \& Chautems 2015, BFG 2018). Assemelha-se a S. cooperi (Paxton) Wiehler pela morfologia das folhas e flores bilabiadas, diferenciando-se por apresentar hábito terrícola ou rupícola e caule ereto (vs. S. cooperi que apresenta hábito epifítico ou rupícola, caule pendente ou decumbente). $\mathrm{O}$ período de floração ocorre entre os meses de fevereiro a maio (Chautems \& Matsuoka 2003). Na Serra foi observada em floração nos meses de novembro a março, coletada em afloramentos rochosos no campo de altitude ca. $1480 \mathrm{~m}$ de altitude.

Material examinado: BRASIL. MinAS GERAIS: Caldas, Pocinhos do Rio Verde, Serra da Pedra Branca, 3-III-1874, fl., A.F.Regnell 833 (K, P, R); XII-1989, fl., A. Chautems et al. 364 (G, SP); 27-II-2008, fl., M.G. Rezende et al. 2 (CESJ); 3-III-2008, fl., M.G. Rezende et al. 12 (CESJ, G); 28-III-2008, fr., M.G. Rezende et al. 34 (CESJ); Pedreira Califórnia Brown, 23-I-2009, fl., M.G. Rezende et al. 325 (CESJ, G).

5. Sinningia striata (Fritsch) Chautems, Gesneriana 1(1): 11. 1995.

Figuras 2f, g e h

Erva rupícola; caule aéreo $25-30 \mathrm{~cm}$ compr., herbáceo, anual, ereto, avermelhado, simples ou ramificado, velutino, tricomas alvos. Folhas 3-verticiladas, levemente anisófilas; pecíolo 4-7 mm compr., pubescente; lâmina 4-7 × 2,5-4 cm, verde, elíptica a lanceolada, cartácea, ápice agudo, base lanceolada, margem crenada a serreada, face adaxial velutina, face abaxial geralmente vinácea, velutinopubescente; 5-6 pares de nervuras secundárias. Inflorescência com pedúnculo de 1,3-5,2 cm compr., cimeiras de 3-7 flores por axila. Flores pediceladas, pedicelo 1,2-2 cm compr., vináceo, velutino; cálice avermelhado, sépalas 5-7 × 1-2 mm, triangulares a lanceoladas, margem inteira, pubescente; corola, 2,8-3,5 cm compr., tubulosa, não bilabiada, rosaclaro com máculas rosa-escuro na parte internado tubo, pubescente a velutina, base intumescida com 2 protuberâncias dorsalmente, em seguida abruptamente constrita, depois progressivamente alargada, com lacínios subiguais, glabrescentes; estames inclusos, filetes creme, ca. 3,0 cm compr.; anteras unidas em retângulo, estilete ca. $2,8 \mathrm{~cm}$ compr., avermelhado; nectário formado de 2 glândulas dorsais, unidas. Frutos ca. 2,5 cm compr., ovoides, secos do tipo cápsula.

Sinningia striata é endêmica da Floresta Atlântica, em Minas Gerais (BFG 2018), restrita às serras próximas a Poços de Caldas e na Serra da Pedra Branca, em Caldas, considerada ameaçada de extinção na categoria Vulnerável (Chautems et al. 2013). Diferencia-se de $S$. douglasii por apresentar hábito terrícola ou rupícola e folhas 3-verticiladas (vs. hábito epífitico e folhas 6-verticiladas às vezes encimadas por um segundo verticilo de 3 folhas menores). Floresce em dezembro e janeiro (Perret et al. 2007). Na Serra da Pedra Branca foi observada em floração no mês de novembro a março.

Material examinado: BRASIL. Minas Gerais: Caldas, Pocinhos do Rio Verde, Serra da Pedra Branca, 31-III-1847, fl., A.F.Regnell et al. 831 (R); 10-XII-1873, fl., H. Mosén. 930 (holótipo S); XII-1989, fl., A. Chautems et al. 366 (G, SP); 22-XI-2008, fl. e fr., M.G. Rezende et al. 248 (CESJ, G).

\section{Agradecimentos}

Os autores agradecem ao programa de Pós-graduação em Ecologia da Universidade Federal de Juiz de Fora o apoio nos trabalhos de campo; ao Herbário Leopoldo Krieger (CESJ) pelo apoio logístico; à Dra. Fátima R.G. Salimena, ao colega Diego R. Gonzaga pelas fotos gentilmente cedidas e à CAPES pelo apoio financeiro da bolsa concedida às Primeira e Segunda Autora.

\section{Literatura citada}

Alves, R.J.V. \& Kolbek, J. 2009. Summit vascular flora of Serra de São José, Minas Gerais, Brazil. Check List 5: $35-73$.

Araújo, A. O., Chautems, A. \& Souza, V.C. 2004. Flora da Serra do Cipó, Minas Gerais: Gesneriaceae. Boletim de Botânica da Universidade de São Paulo 22: 43-51.

Araújo, A.O., Souza, A.V.C. \& Chautems, A. 2005. Gesneriaceae da Cadeia do Espinhaço de Minas Gerais, Brasil. Revista Brasileira de Botânica 14: 109-135. 
Araújo, A.O. \& Chautems, A. 2015. Gesneriaceae in Lista de Espécies da Flora do Brasil. Jardim Botânico do Rio de Janeiro. Disponível em http://floradobrasil.jbrj.gov. br/jabot/floradobrasil/ FB119 (10-XI-2018).

Barroso, G.M., Peixoto, A.L., Ichaso, C.L.F., Costa, C.G., Guimarães, E.F. \& Lima, H.C. 1991. Sistemática de Angiospermas do Brasil. v. 3. 2 ed. Universidade Federal de Viçosa, Viçosa.

BFG (Brazil Flora Group). 2018. Brazilian Flora 2020: Innovation and collaboration to meet Target 1 of the Global Strategy for Plant Conservation (GSPC). Rodriguésia 69: 1513-1527.

Blaser, J.G., Eiterer, M., Salimena, F.R.G. \& Chautems, A. 2011. Gesneriaceae do Parque Estadual do Ibitipoca, Minas Gerais, Brasil. Boletim de Botânica da Universidade de São Paulo 29: 1-12.

Blaser, J., Salimena, F.R.G. \& Chautems, A. 2012. Gesneriaceae na Serra Negra, Minas Gerais, Brasil. Rodriguésia 63: 705-714.

Camargo, E., Rodrigues, L.C. \& Araújo, A.C. 2011. Pollination biology and reproduction of Seemannia sylvatica (Kunth) Hanstein (Gesneriaceae) in the Serra da Bodoquena National Park, Mato Grosso do Sul. Biota Neotropica 11: 125-130.

CETEC (Fundação Centro Tecnológico de Minas Gerais). 1983. Diagnóstico ambiental de Minas Gerais. Belo Horizonte. CETEC.

Chautems, A., Araújo, A.O., Sfair, J.C., Barros, F.S.M., Fernandez, E.P., Moraes, M.M.V., Pessoa, S.V.A., Kutschenko, D.C. \& Messina, T. 2013. Gesneriaceae. In: G. Martinelli \& M.A. Moraes (orgs.). Livro vermelho da flora do Brasil. Instituto de Pesquisas Jardim Botânico do Rio de Janeiro, Rio de Janeiro, pp. 553-564.

Chautems, A. 2008. Gesneriaceae. In: F.O. Zuloaga, O. Morrone \& M. Belgrano (eds.). Catálogo de las Plantas Vasculares Del Cono Sur. Monographs in Systematic Botany from the Missouri Botanical Garden. St. Louis, pp. 2338-2354.

Chautems, A. \& Matsuoka, C. Y. K (coord.) . 2003. Gesneriaceae. In: M.G.L. Wanderley, G.J. Shepherd, A. M. Giulietti, T. S. Melhem, T. S. \& M. Kirizawa (eds.). 2003. Flora fanerogâmica do Estado de São Paulo. São Paulo. Instituto de Botânica, pp. 75-103.

Chautems, A. 2000. Gesneriaceae. In: M.M.R.F. Mello, F. Barros, S.A.C. Chiea, M. Kirizawa, S. Jung-Mendacolli \& M.G.L. Wanderley (eds.). Flora Fanerogâmica da Ilha do Cardoso. v. 7. Instituto de Botânica/Secretaria de Estado do Meio Ambiente, São Paulo, pp. 53-69.

Chautems, A. 1993. Gesneriaceae. In: R. Spichiger \& L. Ramella (eds). Flora del Paraguay - 22. Conservatoire et Jardín botaniques de la Ville de Genève \& Missouri Botanical Garden.

Chautems, A. 1991. A família Gesneriaceae na região cacaueira da Bahia, Brasil. Revista Brasileira de Botânica 14: 51-59.
Chautems, A. 1988. Révision taxonomique et possibilités d'hybridations de Nematanthus Schrader (Gesneriaceae), genre endémique de la forêt côtière brésilienne. Dissertationes Botanicae, Berlin.

Conforti, T.B., Ramos, E., Adami, S.F., Rosas, P.F.C., Batista Filho, J.J., Caponi, H.L. \& Pardalis, A.A. 2007. Zoneamento da A.P.A. "Santuário Ecológico da Pedra Branca", Unidade de Conservação Municipal, Caldas, Minas Gerais, pp. 116.

Drummond, G.M., Martins, C.S., Machado, A.B.M., Sebaio, F.A. \& Antonini, Y. 2005. Biodiversidade em Minas Gerais: um atlas para sua conservação. 2 ed. Fundação Biodiversitas, Belo Horizonte, pp. 534.

Köppen, W \& Geiger, R. 1928. Klimate der Erde Gotha: Verlag Justus Perthes.

Leoni, L.S., Rocha, M.J.R. \& Chautems, A. 2004. Flora Fanerogâmica do Parque Nacional do Caparaó: Gesneriaceae. Pabstia 3: 1-11.

Leoni, L.S., Rocha, M.J.R. \& Chautems, A. 2005. Flora Fanerogâmica do Parque Estadual da Serra do Brigadeiro: Gesneriaceae. Pabstia 3: 1-12.

Mota Machado, T. \& Menini Neto, L. 2010. Bromeliaceae de um campo de altitude no sul de Minas Gerais (Brasil). Fontqueria 56: 109-124.

Pansarin, E.R. \& Pansarin, L.M. 2018. Specificity and influence of climatic factors on the pollination of south-eastern Brazilian Sinningia. Australian Journal of Botany 66: 468-478.

Pereira, L.C., Chautems, A., Mello, R.M. \& Menini Neto, L. 2013. Gesneriaceae no Parque Estadual da Serra do Papagaio, Minas Gerais, Brasil. Boletim de Botânica da Universidade de São Paulo 31: 1-12.

Perret, M., Chautems, A. \& Spichiger, R. 2006. Dispersal-vicariance analyses in the tribe Sinningieae (Gesneriaceae): A clue to understanding biogeographical history of the Brazilian Atlantic forest. Annals of the Missouri Botanical Garden 93: 340-358.

Perret, M., Chautems, A., Spichiger, R., Barraclough, T. G. \& Savolainen, V. 2007. The geographical pattern of speciation and floral diversification in the Neotropics: the Tribe Sinningieae (Gesneriaceae) as a case study. Evolution 61: 1641-1660.

Rezende, M.G., Elias, R.C.L., Salimena, F.R.G. \& Menini Neto, L. 2013. Flora vascular da Serra da Pedra Branca, Caldas, Minas Gerais e relações florísticas com áreas de altitude da Região Sudeste do Brasil. Biota Neotropica 13: 201-224.

Rosa, A.E.M. \& Monteiro, R. 2012. Bromeliaceae na A.P.A. Santuário Ecológico da Pedra Branca, Caldas, Minas Gerais. Boletim de Botânica da Universidade de São Paulo 31: 1-4. 
Serrano-Serrano, M.L., Rolland, J., Clark, J.L., Salamin, N. \& Perret, M. 2017. Hummingbird pollination and the diversification of angiosperms: an old and successful association in Gesneriaceae. Proceedings of the Royal Society B: Biological Sciences 284: 1-10.

Souza, V.C. \& Lorenzi, H. 2012. Botânica Sistemática Guia ilustrado para identificação das famílias de Fanerógamas nativas e exóticas no Brasil, baseado em APG III. 3 ed. Instituto Plantarum, Nova Odessa, São Paulo.
Várzea, A. 1942. Relevo do Brasil. Revista Brasileira de Geografia 4: 97-130.

Weber, A. Clark, J. L. \& Möller, M. 2013. A New Formal Classification of Gesneriaceae. Selbyana 31: 68-94.

Wiehler, H.J. 1983. A Synopsis of the Neotropical Gesneriaceae. Selbyana 6: 1-219.

Wiehler, H.J. 1995. New species of Gesneriaceae from the Neotropics-II. Gesneriana 1: 29-97. 